\title{
Estudo fisiográfico da sub-bacia pertencente à bacia do Rio Turvo-Santa Rosa- Santo Cristo, Rio Grande do Sul
}

\author{
Morgana Vigolo ${ }^{*}$, Bianca Breda ${ }^{b}$, Taison Anderson Bortolin ${ }^{c}$ \\ a Universidade de Caxias do Sul, Rio Grande do Sul, Caxias do Sul, CEP 95070-560, Brasil. \\ *mvigolo1@ucs.br \\ b Universidade de Caxias do Sul, Rio Grande do Sul, Caxias do Sul, CEP 95070-560, Brasil. \\ c Instituto de Saneamento Ambiental da Universidade de Caxias do Sul, Rio Grande do Sul, Caxias do Sul, CEP 95070-560, Brasil.
}

Recebido: 3 abril 2019 / Aceito: 5 maio 2019 / Publicado online: 27 maio 2019

\begin{abstract}
Resumo
A análise fisiográfica de uma bacia hidrográfica é fundamental para o entendimento hidrológico. O objetivo da pesquisa foi determinar e avaliar as características fisiográficas de uma sub-bacia pertencente a bacia hidrográfica dos Rios Turvos-Santa Rosa-Santo Cristo, localizada ao norte-noroeste do estado do Rio Grande do Sul, Brasil, a partir do uso de ferramentas SIG e representar o uso e ocupação do solo na região. A sub-bacia apresentou área de $31,40 \mathrm{~km}^{2}$, perímetro de $34,60 \mathrm{~km}$, comprimento total do rio principal de $9,96 \mathrm{~km}$ e fator de forma igual a 0,40 . O ordenamento dos rios resultou em ordem 3 , com densidade de rios de 0,797 segmentos $/ \mathrm{km}^{2}$. A declividade média do rio principal foi determinada em 12,85\%, com tempo de concentração de 2,07 horas. Define-se então a sub-bacia como alongada, tendendo por um escoamento rápido, possuindo drenagem satisfatória e relevo ondulado. Os principais usos do solo estão associados a solo exposto e agricultura que correspondem a 62,5\% e mata nativa, com $37,52 \%$. Infere-se que a principal demanda de água seja em atividades agrícolas e o estudo do comportamento hidrológico consiste em uma ferramenta de planejamento para gestão dos recursos hídricos.
\end{abstract}

Palavras-chave: Bacia hidrográfica, fisiografia, hidrologia, Salvador das Missões, ocupação do solo.

\section{Physiographic study of subbasin belonging to the Turvo-Santa Rosa-Santo Cristo River basin, Rio Grande do Sul}

\begin{abstract}
The objective of this research was to determine and evaluate the physiography characteristics in the subbasin belonging to the Turvo-Santa Rosa-Santo Cristo river basin, located in the northwest in the Rio Grande do Sul State, Brazil, using GIS tools and to represent the use and occupation of the soil in the region. The sub-basin presented an area of $31.40 \mathrm{~km}^{2}$, perimeter of 34.60 $\mathrm{km}$, total length of the main river of $9.96 \mathrm{~km}$ and a form factor of 0.40 . The ordering of the rivers resulted in order 3 , with a river density of 0.797 segments $/ \mathrm{km}^{2}$. The average slope of the main river was determined at $12.85 \%$, with a concentration time of 2.07 hours. The sub-basin is then defined as elongated, tending through a fast flow, having satisfactory drainage and undulating landform. The main uses of the soil are associated with exposed soil and agriculture that correspond to $62.5 \%$ and native forest, with $37.52 \%$. It is inferred that the mainly water demand is in agricultural activities and the study of hydrological behavior consists of a planning tool for water resources management.
\end{abstract}

Keywords: Hydrographic basin, physiography, hydrology, Salvador das Missões, occupation of soil.

\section{Introdução}

O comportamento natural da água e suas transformações, ocorrências e relações com a vida humana é caraterizada através do conceito de ciclo hidrológico, que pode ser definido como "fenômeno global de circulação fechada da água entre a superfície terrestre e a atmosfera" (Tucci, 2013). Estuda-se a hidrologia com ênfase na fase terrestre, onde toma-se como elemento principal a bacia hidrográfica, que é uma área de captação natural da água da precipitação, compartimentada naturalmente pelo relevo, onde $o$ escoamento converge para um único ponto, o exutório
(Taveira, 2018).

A obtenção de dados consistentes e a realização de estudos hidrológicos são primordiais para que ocorra a gestão adequada de bacias hidrográficas, pois permitem o diagnóstico da situação atual, a análise de alternativas para o crescimento demográfico e modificações do uso do solo, o balanço entre disponibilidade e demandas futuras por água em quantidade e qualidade, as metas para a racionalização de uso e programas a serem desenvolvidos, bem como criação de áreas sujeitas à restrição de utilização, com vistas à proteção dos recursos hídricos (Poleto, 2014). 
Conforme Cunha e Bacani (2016), estudos relacionados à drenagem fluvial sempre desempenharam um papel central nos estudos hidrológicos que buscam compreender a ocorrência, distribuição e movimentação da água e suas propriedades. A análise fisiográfica é um conjunto de procedimentos que caracterizam os aspectos geométricos e composicionais dos sistemas ambientais, servindo como indicadores da interação entre os aspectos geomorfológicos e a rede de canais fluviais em uma bacia hidrográfica.

Segundo Santos (2018), a expansão das áreas produtivas, o aumento dos aglomerados urbanos e a exploração dos recursos naturais que visam suprir as necessidades humanas provocam rápidas alterações na cobertura do solo e na topografia local que, aliadas ao desenvolvimento contínuo e mal planejado, geram consequências socioeconômicas e ambientais. As análises de uso e ocupação do solo se fazem necessárias a fim de obter informações sobre o panorama atual, nos quais permitem propor medidas para mitigar impactos e melhorar a gestão dos recursos hídricos, impedindo a expansão desordenada, preservando os leitos dos rios e mantendo os ecossistemas imunes a esses efeitos.

Em virtude da importância de quantificar e qualificar os aspectos fisiográficos das bacias hidrográficas, destaca-se a utilização dos Sistemas de Informações Geográficas - SIGs, que é um recurso tecnológico ligado ao uso de geoprocessamento que dá suporte aos diversos estudos ambientais. A espacialização dos dados, através de imagens de satélite, mapas topográficos e mapas geológicos, é essencial para a realização de análises complexas e serve também como uma orientação das ações voltadas aso planejamento e organização de territórios (Garcia, 2014).

Esta pesquisa buscou determinar e avaliar as características fisiográficas de uma sub-bacia pertencente a bacia hidrográfica dos Rios Turvos-Santa Rosa-Santo Cristo, localizada ao norte-noroeste do estado do Rio Grade do Sul, Brasil, a partir do uso de ferramentas SIG e representar o uso e ocupação do solo na região.

\section{Material e Métodos}

\section{Área de estudo}

A sub-bacia situa-se a norte-noroeste do estado do Rio Grande do Sul, no município de Salvador das Missões, com as coordenadas geográficas de seu exutório sendo de $-28,04$ latitude Sul e de -54,84 longitude Oeste. A sub-bacia pertence a bacia hidrográfica dos Rios Turvos-Santa Rosa-Santo Cristo, que encontra-se entre as coordenadas geográficas de 27,12 a -28,22 latitude Sul e -53,40 a -55,33 de longitude Oeste. A bacia abrange 55 municípios, possui uma área de drenagem de $10.753,83 \mathrm{~km}^{2}$, e seus principais formadores são os rios Amandaú, Buricá, Comandaí, Lajeado Grande, Santo Cristo, Santa Rosa, Turvo e outros afluentes menores que drenam diretamente para o Rio Uruguai (FEPAM, 2019).

A bacia hidrográfica dos Rios Turvos-Santa Rosa-Santo Cristo compõe uma das dez unidades hidrográficas que formam a Região Hidrográfica Brasileira do Uruguai, (Figura 1), ocupando cerca de $3 \%$ do território brasileiro, abrangendo porções dos estados do Rio Grande do Sul e Santa Catarina. Em território sul-rio-grandense a mesma abrange a porção norte, noroeste e oeste, com uma área de aproximadamente $127.031,13 \mathrm{~km}^{2}$.
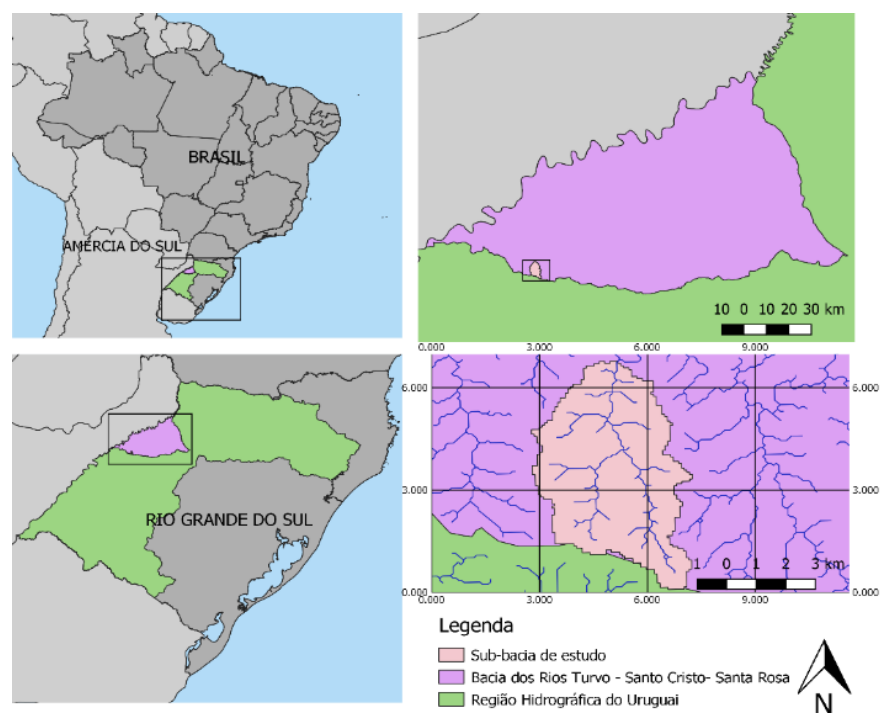

Figura 1. Mapa de localização da sub-bacia em relação a região hidrográfica do Uruguai e a sub-bacia hidrográfica dos Rios Turvos-Santa Rosa-Santo Cristo (2018)

\section{Parâmetros Fisiográficos}

A análise fisiográfica abrange um grande número de parâmetros que permitem melhor caracterizar o ambiente de uma bacia, sua predisposição para ocorrência de eventos, sua incompatibilidade para certas atividades humanas e com modelos de uso e ocupação do solo (Machado \& Torres, 2013). De acordo com Back (2014), as características da bacia hidrográfica como tamanho, forma, declividade e tempo influenciam no comportamento hidrológico.

Durante o período de setembro a novembro de 2018, coletou-se dados com auxílio de ferramentas SIG, que incluem o software IDRISI para auferir características físicas e o QGIS para elaboração de mapas. A partir do IDRISI delimitou-se a sub-bacia hidrográfica de interesse e obteve-se a área, que é um elemento básico para o cálculo de outros parâmetros, juntamente com o perímetro, comprimento axial (Lb) e comprimento do rio principal da bacia hidrográfica já delimitada (Back, 2014). Para o conhecimento morfométrico da sub-bacia, determinou-se índices como o coeficiente de compacidade (kc), fator de forma (I) e índice de circularidade (Ic).

Foram também levantadas informações relacionadas ao sistema de drenagem como: número total de sgmentos $(\mathrm{Nt})$, comprimento total da rede de drenagem (Lt), a densidade de drenagem (Dd), extensão média do escoamento superficial (Les), densidade de rios (Dr) e coeficiente de manutenção $(\mathrm{Cm})$. O ordenamento de canais de drenagem foi realizado a partir do método de Strahler (1957), que consiste na hierarquização dos canais fluviais, evitando a subjetividade de classificação das nascentes (Back, 2014).

A declividade média do rio principal ( $\mathrm{Sm}$ ), característica do relevo da bacia, no qual influencia diretamente na velocidade do escoamento superficial, foi determinada mediante o ponto com maior declividade da bacia (Z100) e o ponto de menor 
declividade (Z0), ambos obtidos a partir da curva hipsométrica fornecida pelo IDRISI. $O$ tempo de concentração, período de tempo necessário para que toda água que chegou na bacia dirija-se até o exutório, relacionado diretamente com a maioria das características morfométricas da sub-bacia de estudo, foi determinado pelo método de Kirpich, que é uma das equações mais utilizadas para bacias rurais (Taveira, 2018). Os parâmetros avaliados no levantamento fisiográfico da sub-bacia estão especificados na Tabela 1.

Tabela 1. Equações utilizadas para determinar os parâmetros fisiográficos da sub-bacia.

\begin{tabular}{|c|c|}
\hline Equação & Definição das Variáveis \\
\hline $\mathrm{Kc}=0,28 \frac{\mathrm{P}}{\sqrt{\mathrm{A}}}$ & $\begin{array}{l}\text { Kc: coeficiente de compacidade; } \\
\text { P: Perímetro }(\mathrm{m}) \text {; } \\
\text { A: Área de drenagem }\left(\mathrm{m}^{2}\right)\end{array}$ \\
\hline$I=\frac{A}{L b^{2}}$ & $\begin{array}{l}\mathrm{I}=\text { Fator de Forma; A: Área de } \\
\text { drenagem }\left(\mathrm{m}^{2}\right) ; \mathrm{Lb} \text { : Comprimento } \\
\text { axial da sub-bacia }(\mathrm{m}) .\end{array}$ \\
\hline $\mathrm{I}_{\mathrm{c}}=\frac{4 \pi \mathrm{A}}{\mathrm{P}^{2}}$ & $\begin{array}{l}\text { Ic: Índice de circularidade; } \\
\text { A: Área de drenagem }\left(\mathrm{m}^{2}\right) \text {; } \\
\text { P: Perímetro }(\mathrm{m}) \text {. }\end{array}$ \\
\hline $\mathrm{Dd}=\frac{\mathrm{Lt}}{\mathrm{A}}$ & $\begin{array}{l}\text { Dd: Densidade de Drenagem } \\
\left(\mathrm{km} / \mathrm{km}^{2}\right) ; \mathrm{Lt} \text { : Comprimento total } \\
\text { da rede de drenagem }(\mathrm{km}) ; \\
\text { A: Área de drenagem }\left(\mathrm{km}^{2}\right) .\end{array}$ \\
\hline $\mathrm{Les}=\frac{\mathrm{A}}{4 \mathrm{Lt}}$ & $\begin{array}{l}\text { Les: extensão média do } \\
\text { escoamento superficial }(\mathrm{km}) \text {; } \\
\text { A: Área de drenagem }\left(\mathrm{km}^{2}\right) ; \\
\text { Lt: Comprimento total da rede de } \\
\text { drenagem }(\mathrm{km}) .\end{array}$ \\
\hline $\mathrm{Dr}=\frac{\mathrm{Nt}\left(1^{\mathrm{a}} \text { ordem }\right)}{\mathrm{A}}$ & $\begin{array}{l}\text { Dr: Densidade de Rios } \\
\left(\text { segmentos } / \mathrm{km}^{2}\right) ; \mathrm{Nt} \text { : Número de } \\
\text { segmentos de } 1^{\mathrm{a}} \text { ordem; } \\
\text { A: Área de drenagem }\left(\mathrm{km}^{2}\right) .\end{array}$ \\
\hline $\mathrm{C}_{\mathrm{m}}=\frac{1}{\mathrm{Dd}}$ & $\begin{array}{l}\text { Cm: Coeficiente de Manutenção } \\
\left(\mathrm{km}^{2} / \mathrm{km}\right) ; \text { Dd: Densidade de } \\
\text { Drenagem }\left(\mathrm{km} / \mathrm{km}^{2}\right) .\end{array}$ \\
\hline $\mathrm{Sm}=\frac{\mathrm{Z}_{100}-\mathrm{Z}_{0}}{\mathrm{~L}}$ & $\begin{array}{l}\text { Sm: Declividade média do Rio } \\
\text { Principal }(\mathrm{m} / \mathrm{m}) ; \mathrm{Z}_{100} \text { : ponto com } \\
\text { maior declividade da bacia }(\mathrm{m}) ; \\
\mathrm{Z}_{0} \text { : ponto de menor declividade } \\
(\mathrm{m}) ; \mathrm{L} \text { : Comprimento do Rio } \\
\text { Principal }(\mathrm{m}) \text {. }\end{array}$ \\
\hline $\mathrm{Tc}=57\left(\frac{\mathrm{L}^{3}}{\Delta \mathrm{H}}\right)^{0,385}$ & $\begin{array}{l}\text { Tc: Tempo de concentração } \\
\text { (min); L: Comprimento do Rio } \\
\text { Principal }(\mathrm{km}) ; \\
\Delta \mathrm{H} \text { : Diferença de altitude ao } \\
\text { longo do talvegue }(\mathrm{m}) .\end{array}$ \\
\hline
\end{tabular}

Fonte: Back (2014).

\section{Uso e ocupação do solo}

O mapeamento do uso do solo foi realizado através de imagens de satélite Landsat 8 com data de 29 de outubro de 2018, disponibilizados no site do serviço geológico dos Estados Unidos (USGS, 2018). Esses dados foram trabalhados com o software IDRISI, o qual possibilitou caracterizar os diferentes tipos e formas de ocupação de solo da região, além de definir a porcentagem de área para cada tipo de solo presente na região de estudo.

\section{Resultados e Discussão}

As características fisiográficas da sub-bacia hidrográfica em estudo estão descritos na Tabela 2.

Tabela 2. Resultados obtidos para os parâmetros fisiográficos da sub-bacia hidrográfica dos Rios TurvosSanta Rosa-Santo Cristo.

\begin{tabular}{lc}
\hline \multicolumn{1}{c}{ Índice Fisiográfico } & Valor \\
\hline Área (A) & $31,40 \mathrm{~km}^{2}$ \\
\hline Perímetro (P) & $34,60 \mathrm{~km}$ \\
\hline Comprimento Axial (Lb) & 8,86 \\
\hline Coeficiente de compacidade (Kc) & 1,73 \\
\hline Fator de forma (I) & 0,40 \\
\hline Índice de circularidade (Ic) & 0,33 \\
\hline Comprimento do rio principal (L) & $9,96 \mathrm{~km}$ \\
\hline $\begin{array}{l}\text { Ordenamento dos rios conforme } \\
\text { Strahler (1957) }\end{array}$ & Ordem 3 \\
\hline $\begin{array}{l}\text { Comprimento total da rede de } \\
\text { drenagem (Lt) }\end{array}$ & $32,138 \mathrm{~km}$ \\
\hline $\begin{array}{l}\text { Número total de segmentos de } \\
\text { drenagem (Nt) }\end{array}$ & $47 \mathrm{segmentos}$ \\
\hline Densidade de drenagem (Dd) & $1,024 \mathrm{~km} / \mathrm{km}^{2}$ \\
\hline $\begin{array}{l}\text { Extensão média do escoamento } \\
\text { superficial (Les) }\end{array}$ & $0,244 \mathrm{~km}$ \\
\hline Densidade de rios (Dr) & $0,797 \mathrm{segmentos} / \mathrm{km}^{2}$ \\
\hline Coeficiente de manutenção (Cm) & $0,977 \mathrm{~km} / \mathrm{km}$ \\
\hline Altitude máxima (Z100) & $272 \mathrm{~m}$ \\
\hline Altitude mínima (Z0) & $144 \mathrm{~m}$ \\
\hline Declividade média do rio (Sm) & $12,85 \%$ \\
\hline Tempo de concentração (Tc) & min \\
\hline
\end{tabular}

A área da sub-bacia em questão resultou em $31,40 \mathrm{~km}^{2}$, perímetro de $34,60 \mathrm{~km}$ e comprimento axial de $8,86 \mathrm{~km}$. A classificação da bacia quanto a sua área de drenagem torna-se difícil, devido à definição das dimensões das classes apresentarem algum grau de subjetividade, pois a variabilidade existente nas características físicas das bacias não permite um valor único aplicado para cada situação (Paiva \& Paiva, 2001). No entanto, estima-se que esta enquadra-se no conjunto de pequenas bacias hidrológicas, pois é um valor significativamente inferior a área da bacia do Ribeirão Santo Antônio, considerado por Batista, Cabral, Rocha, e Barbosa (2017) de grande porte, possuindo $651,28 \mathrm{~km}^{2}$.

Encontrou-se o valor de 1,73 para o coeficiente de compacidade e 0,40 para o fator de forma. A forma da bacia interfere diretamente no seu comportamento hidrológico e, principalmente permite prognosticar o processo de escoamento superficial. O coeficiente de compacidade associado ao fator de forma, constituem um indicativo quanto a possibilidade de ocorrência de enchente em uma bacia hidrográfica. Desse modo, compreende-se que a sub-bacia de estudo não está sujeita a grandes enchentes, pois de acordo com valores apresentados por Back (2014) para Kc > 1,5 e I<0,5 a bacia não é propensa a eventos de cheias. 
Para o índice de circularidade obteve-se o valor igual a 0,33. Logo, classifica-se como sub-bacia de forma alongada, favorecendo o processo de escoamento, não contribuindo na concentração de água que provocam inundações, pois conforme explica Back (2014), para valores menores que 0,51 mais distante da forma circular estará a bacia de drenagem.

A curva hipsométrica, além de revelar a declividade longitudinal do rio principal, demonstrou que o seu comprimento total foi de 9,96 km (Figura 2).

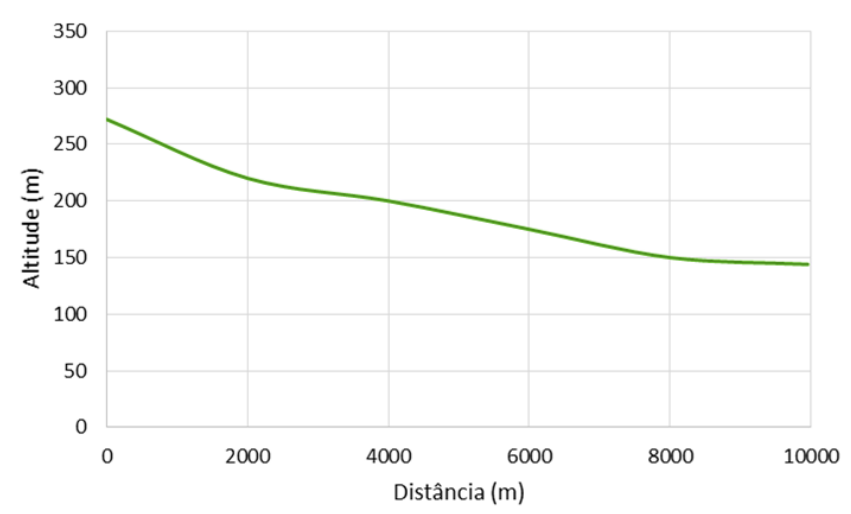

Figura 2. Perfil Longitudinal (declividade e comprimento) do rio principal da sub-bacia sub-bacia hidrográfica dos Rios Turvos-Santa Rosa-Santo Cristo.

O sistema de drenagem é constituído pelo rio principal e todas as suas ramificações que contribuem para o escoamento na bacia hidrográfica (Figura 3).

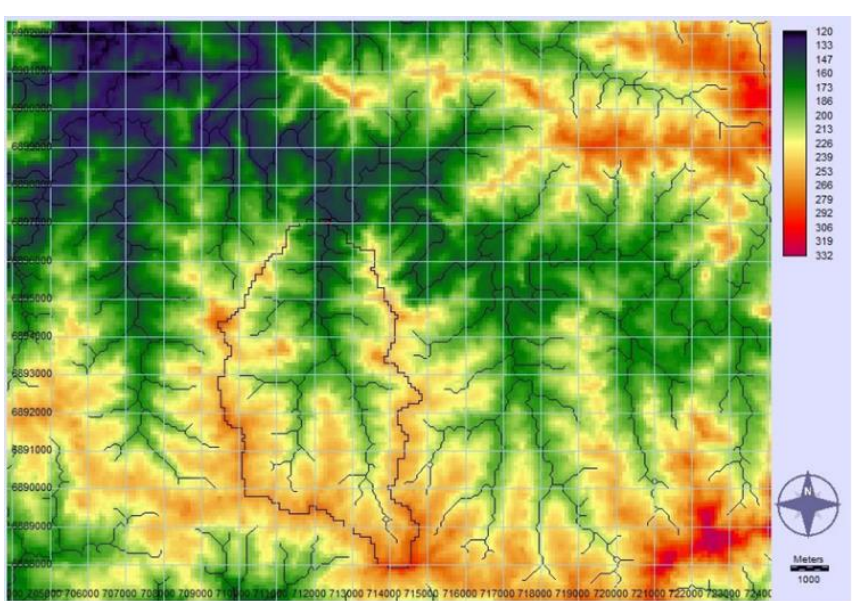

Figura 3. Rio principal e suas ramificações (sistema de drenagem) que compõe a sub-bacia sub-bacia hidrográfica dos Rios Turvos-Santa Rosa-Santo Cristo.

O ordenamento dos rios pelo método de Strahler (1957) obteve a classificação de ordem 3 para a rede de drenagem, conforme apresentado na Figura 4.

O comprimento total levantado para a rede de drenagem foi igual a $32,138 \mathrm{~km}$, contando com 47 segmentos e densidade de drenagem igual a $1,024 \mathrm{~km} / \mathrm{km}^{2}$, permitindo classificar essa como uma bacia de drenagem satisfatória/intermediária, pois de acordo com Back (2014), bacias com densidade de drenagem mediana possuem Dd entre 0,5 a $2,0 \mathrm{~km} / \mathrm{km}^{2}$. Ao comparar com duas bacias hidrográficas do Alto Juruá, que obtiveram valores de 0,83 e $0,86 \mathrm{~km} / \mathrm{km}^{2}$, categorizadas como drenagem deficitária, que respondem lentamente a eventos, pode-se confirmar que o resultado encontrado na sub-bacia de interesse é válido (Silva, Delgado, Souza \& Silva, 2014). A partir do número de segmentos de drenagem, classifica-se a sub-bacia hidrográfica como perene, pois esses cursos d'água contém água durante todo o tempo, devido ao lençol subterrâneo manter a alimentação contínua (Machado \& Torres, 2013).

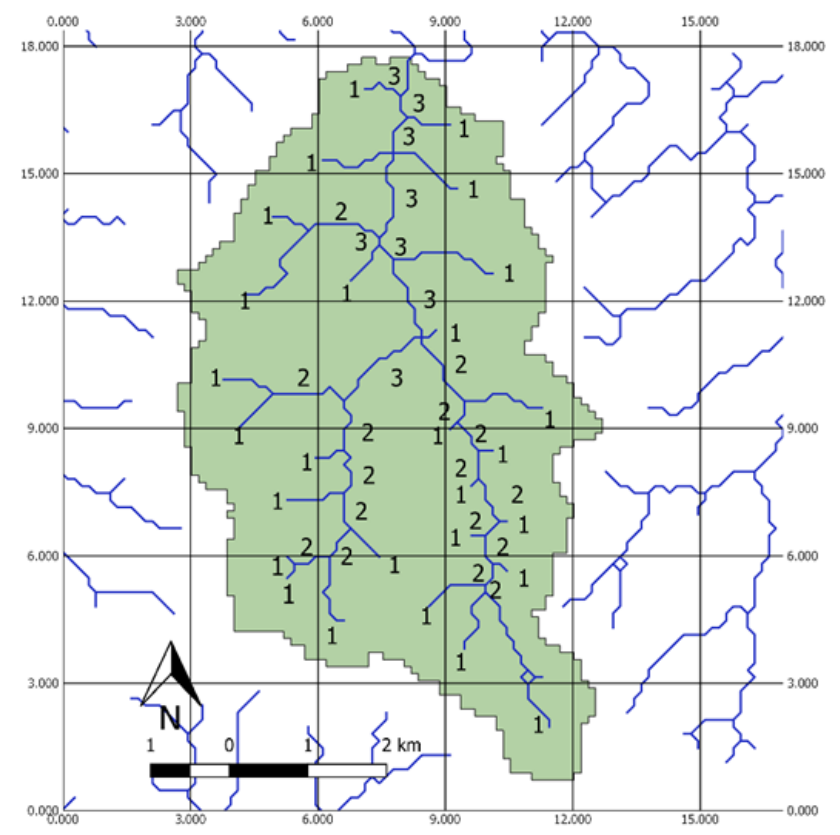

Figura 4. Representação do ordenamento dos rios da subbacia sub-bacia hidrográfica dos Rios Turvos-Santa RosaSanto Cristo, conforme número de ordem (1, 2 e 3$)$ de Strahler (1957).

A extensão média do escoamento superficial foi de 0,244 $\mathrm{km}$, representando a distância que a água percorreria caso o escoamento ocorresse em linha reta; a densidade de rios foi de 0,797 segmentos $/ \mathrm{km}^{2}$, que indica a capacidade de a sub-bacia gerar novos cursos d'água. Desse modo, ao confrontar com o resultado obtido para a bacia hidrográfica do Rio Pequeno, no qual classificaram o valor de 4,52 segmentos/ $\mathrm{km}^{2}$ como densidade alta, pode-se afirmar que a sub-bacia de interesse possui densidade de rios baixa (Soares \& Souza, 2012). Obteve-se o valor de $0,977 \mathrm{~km}^{2} / \mathrm{km}$ para o coeficiente de manutenção, indicando a área necessária para manter ativo um quilômetro de canal fluvial (Machado \& Torres, 2013).

Pelo perfil longitudinal, se quantificou a variação de $272 \mathrm{~m}$ a $144 \mathrm{~m}$ da declividade do talvegue, na qual obteve-se o valor de $12,85 \%(0,1285 \mathrm{~m} / \mathrm{m})$ para a declividade média do rio principal. Compreende-se, que o relevo que compõe a subbacia é ondulado, pois a EMBRAPA (2018) reconhece as seguintes classes de relevo conforme a declividade: Plano (0$3 \%$ ); Suave (3-8\%); Ondulado (8- 20\%); Forte Ondulado (20$45 \%$ ); Montanhoso (45-75\%); Escarpado (> 75\%). No estudo de Ogassawara e Gass (2018) sobre a morfometria dos afluentes principais da bacia hidrográfica do Rio Uruguai, é demostrado que a maior parte da área do médio rio Uruguai, 
onde situa-se a bacia dos Rios Turvo-Santa Rosa-Santo Cristo, apresenta declividade entre $8 \%$ e $20 \%$, confirmando que o resultado obtido está de acordo com as características do local. O perfil longitudinal é um parâmetro interferente na velocidade do escoamento, pois quanto maior a declividade maior será a velocidade de escoamento (Back, 2014). O tempo de concentração encontrado foi de 2,07 horas, remetendo-se principalmente pela forma alongada e ao relevo da sub-bacia.

O solo da região hidrográfica de interesse é caracterizado por latossolo roxo distrófico (Strieder, 2006). Segundo Sartori, Neto e Genovez (2005), define-se o solo como grupo hidrológico B, que consiste em um solo menos permeável, arenoso, menos profundo e com capacidade de infiltração média, o que contribui para escoamentos rápidos e concentra a maior parte das precipitações nos cursos d'água. O mapa de uso e ocupação do solo é apresentado na Figura 5.

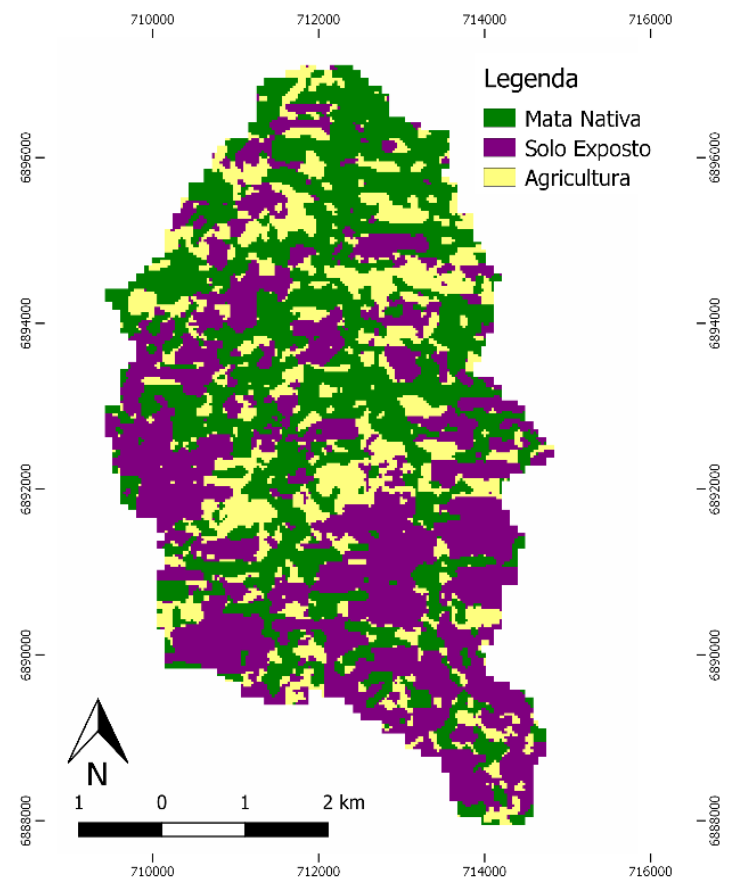

Figura 5. Mapa de uso e ocupação do solo da subbacia sub-bacia hidrográfica dos Rios Turvos-Santa Rosa-Santo Cristo.

Com a aplicação do método analítico, definiu-se que a sub-bacia localiza-se na zona rural do município, sendo a porção de ocupação urbana desconsiderada devido a sua baixa presença. Obteve-se $12,1 \mathrm{~km}^{2}$ para a ocupação de solo exposto, sendo este o mais representativo, com $38,54 \%$. Muito similar ao anterior, a mata nativa com área de 11,78 $\mathrm{km}^{2}$, correspondendo a $37,52 \%$. Já a agricultura, apresentou um valor de $7,52 \mathrm{~km}^{2}$, sendo $23,95 \%$ do território total da sub-bacia.

Quanto à ocupação significativa de solo exposto nessa região destaca-se conforme Silva et al., (2014) que "a remoção ou alteração da vegetação florestal em determinado ambiente pode influenciar os processos erosivos e até mesmo propagar-se para ambientes adjacentes. A declividade e a cobertura vegetal são fatores significativos que auxiliam a tomada de decisão e o manejo da bacia hidrográfica considerando que essas alterações influenciam a precipitação efetiva, o escoamento superficial e o fluxo da água no solo, dentre outros."

Ressalta-se também, que a remoção intensa de detritos das vertentes, por causa das práticas agrícolas de utilização das terras, e a forma da utilização dos cursos d'água estão relacionados com a sedimentação nos leitos dos rios, fator que altera a intensidade de cheias e o regime fluvial (Christofoletti, 1981). Em áreas de solo exposto, onde a cobertura vegetal foi retirada em sua totalidade, ocorrem processos erosivos e todo esse material lixiviado passa a ser transportado para a rede hidráulica, afetando a forma e a velocidade do escoamento e contribuindo para o assoreamento dos rios. A presença de área nativa, por ser significativa, indica que possuem áreas totalmente preservadas em condições naturais, o que torna um lugar menos suscetível aos efeitos antrópicos danosos.

\section{Conclusões}

A sub-bacia analisada, pertencente à bacia hidrográfica dos Rios Turvos-Santa Rosa-Santo Cristo, possui forma alongada, tendência ao escoamento rápido e pouco suscetível a enchentes. Quanto a rede hidrográfica, apresenta drenagem intermediária, sendo satisfatória para o ponto de vista de probabilidade de cheias. $\mathrm{O}$ aspecto topográfico do local, exibe um perfil de declividade média igual a $12,85 \%$, na qual indica um relevo ondulado, contribuindo para o tempo de permanência da água ser moderado alto, que é afirmado também pela forma alongada da sub-bacia de estudo. Supõese, que a principal demanda de água seja em atividades agrícolas, devido a baixa ocupação urbana na sub-bacia e significante extensão ocupada pela agricultura.

Este estudo implica no aumento da base de dados referentes à fisiografia de bacias hidrográficas, principalmente no Estado do Rio Grande do Sul. Além disso, estudar o comportamento hidrológico consiste em uma das principais ferramentas na gestão dos recursos hídricos, devido à possibilidade de prever eventos futuros e ter um planejamento adequado e seguro para as obras hidráulicas.

\section{Referências}

Back, A.J. (2014). Bacias hidrográficas: classificação e caracterização física. Florianópolis: EPAGRI.

Batista, D., Cabral, J.B., Rocha, T., \& Barbosa, G. (2018). Caracterização morfométrica da bacia hidrográfica do ribeirão Santo Antônio - go. Geoambiente On-Line, 2017(29). doi: https://doi.org/10.5216/revgeoamb.v0i29.50882.

Christofoletti, A. (1981). Geomorfologia fluvial. São Paulo: E. Blücher.

Cunha, E.R., \& Bacani, V.M. (2016). Morphometric Characterization of a Watershed through SRTM Data and Geoprocessing Technique. Journal of Geographic Information System, 8, 238-247. https://file.scirp.org/pdf/JGIS_2016042614211097.pdf.

Fundação Estadual de Proteção Ambiental Henrique Luiz Roessler (FEPAM) (2002). U30 - turvo / santa rosa / santo cristo. Recuperado de http://www.fepam.rs.gov.br/qualidade/bacia_uru_turvo.asp

Garcia, M.C.P. (2014). Aplicação do sistema de informações geográficas em estudos ambientais. Curitiba: InterSaberes.

Machado, P.J.O., \& Torres, F.T.P. (2013). Introdução a hidrogeografia. São Paulo: Cengage Learning.

Paiva, J.B.D., \& Paiva, E.M.C.D. (2001). Hidrologia aplicada à gestão de pequenas bacias hidrográficas. Porto Alegre: ABRH. 
Vigolo, et al. - Estudo fisiográfico de sub-bacia

Poleto, C. (2014). Bacias hidrográficas e recursos hídricos. Rio de Janeiro: Editora Interciência. Recuperado de https://bv4.digitalpages.com.br/?term=Bacias\%2520hidrogr\%25C3\%2 5A1ficas $\% 2520 \mathrm{e} \% 2520$ recursos $\% 2520 \mathrm{~h} \% 25 \mathrm{C} 3 \% 25 \mathrm{ADdricos} \& \mathrm{search}$ page $=1 \&$ filtro $=$ todos $\&$ from $=$ busca $\&$ page $=-$ 4\&section=0\#/legacy/41942.

Santos, L.A.C. (2018). Utilização dos dados do Cadastro Ambiental Rural na análise de conflitos de uso do solo em Áreas de Preservação Permanente. Goiânia: Tecnia, revista de educação, ciência e tecnologia do IFG, 3(1). http://revistas.ifg.edu.br/tecnia/article/view/174/77

Strahler, A.N. (1957). Quantitative analysis of watershed geomorphology. Transactions. American Geophysics Union, 38, 913-20. doi: https://doi.org/10.1029/TR038i006p00913

Strieder, I.T. (2006). Análise do saneamento básico e das áreas de conflito de uso da terra no município de Salvador das Missões/RS (Dissertação de Mestrado). Universidade Federal de Santa Maria, Santa Maria, RS, Brasil. Recuperado de http://w3.ufsm.br/ppggeo/files/dissertacoes_0611/Ivete\%20Teresinha\%20Strieder.pdf.

Silva, E.R., Delgado, R.C., Souza, L.P., \& Silva, I.S. (2014). Caracterização física em duas bacias hidrográficas do Alto Juruá, Acre. Revista Brasileira de Engenharia Agrícola e Ambiental, 18(7), 714-719. doi: https://dx.doi.org/10.1590/S1415-43662014000700007

Soares, M. R. G. J, \& Souza, J. L. M. (2012). Análise morfométrica da bacia hidrográfica do rio Pequeno em São José dos Pinhais (PR). Revista Geografia (Londrina), 21(1) 2447-1747. Recuperado de http://www.uel.br/revistas/uel/index.php/geografia/article/view/8982/1 2668.

Taveira, B.D.A. (2018). Hidrogeografia e gestão de bacias. (1a ed.) Curitiba: Editora InterSaberes. Recuperado de https://bv4.digitalpages.com.br/?term=hidrogeografia\&searchpage $=1 \&$ filtro=todos \& from $=$ busca \&page $=4 \&$ section $=0 \# /$ legacy $/ 158944$

Tucci, C.E.M. (2013). Hidrologia: Ciência e Aplicação. (4a ed.) Porto Alegre: UFRGS/ABNRH.

USGS, US Geological Survey. (2019). ErthExplorer - Home. Recuperado de https://earthexplorer.usgs.gov/

Licença Creative Commons CC BY 4.0

Este artigo foi publicado com acesso aberto para distribuíção sob os termos do Licença de Atribuição Creative Commons, que permite uso irrestrito, distribuição, e reprodução em qualquer meio, desde que o trabalho original seja devidamente citado. 